\title{
A novel method to obtain accurate length estimates of carnivorous reef fishes from a single video camera
}

\author{
Gastón A. Trobbiani ${ }^{1,2}$ and Leonardo A. Venerus ${ }^{2}$
}

In the last years, technological advances enhanced the utilization of baited underwater video (BUV) to monitor the diversity, abundance, and size composition of fish assemblages. However, attempts to use static single-camera devices to estimate fish length were limited due to high errors, originated from the variable distance between the fishes and the reference scale included in the scene. In this work, we present a novel simple method to obtain accurate length estimates of carnivorous fishes by using a single downward-facing camera baited video station. The distinctive feature is the inclusion of a mirrored surface at the base of the stand that allows for correcting the apparent or "naive" length of the fish by the distance between the fish and the reference scale. We describe the calibration procedure and compare the performance (accuracy and precision) of this new technique with that of other single static camera methods. Overall, estimates were highly accurate (mean relative error $=-0.6 \%$ ) and precise (mean coefficient of variation $=3.3 \%$ ), even in the range of those obtained with stereo-video methods.

En los últimos años, los avances tecnológicos permitieron intensificar el uso de estaciones de video fijas para estudiar la abundancia, composición de especies y estructura de tamaños de los ensambles ícticos. Sin embargo, la utilización de una única cámara estática para estimar el tamaño de los peces puede conducir a determinaciones poco exactas, provocadas por la distancia variable entre los peces y la escala de referencia incluida en la escena. En este trabajo presentamos un método novedoso para obtener estimaciones exactas del largo de peces carnívoros, que utiliza una estación de video fija con una única cámara orientada verticalmente. La característica que distingue a este sistema es la inclusión de una superficie espejada en la base del soporte de la cámara que permite corregir la longitud aparente o "naive" en función de la distancia entre los peces y la escala de referencia. En este trabajo describimos el procedimiento de calibración y comparamos el rendimiento de esta técnica (exactitud y precisión) con la de otros métodos que utilizan una única cámara estática. Las estimaciones obtenidas fueron exactas (error relativo promedio $=-0,6 \%$ ) y precisas (coeficiente de variación promedio $=3,3 \%$ ), en el rango de valores obtenidos con estéreo-video.

Keywords: Rocky reefs, Acanthistius patachonicus, Underwater video, Fish monitoring, Fish length distribution.

\section{Introduction}

The use of non-invasive monitoring techniques capable of gathering unbiased information about the system state variable(s) (Yoccoz et al., 2001) is crucial to provide support for the management of aquatic resources and to evaluate the effectiveness of marine protected areas, as well as the direct (i.e., extractive and non-extractive uses) and indirect (i.e., sewage discharges, oil spills) effects of the anthropogenic activities in ecologically fragile systems (Langlois et al., 2006). Paradoxically, although abundance and size structure are frequently used as indicators of the health of animal populations, accurate and precise length and abundance data are difficult to obtain for mobile organisms like fishes, which occupy a variety of habitats and show distinct behavioral patterns over a range of spatial and temporal scales (Thresher \& Gunn, 1986; Harvey et al., 2001a; Thompson \& Mapstone, 2002; Irigoyen et al., 2013). As a consequence, the assessment is hampered by the errors and biases inherent to the monitoring methods used, which may reduce the statistical power to detect small but still biologically important changes (Willis \& Babcock, 2000; Harvey et al., 2001b).

Over the last 60 years, underwater video technology has been successfully applied to a wide variety of objectives (Cappo, 2010; Mallet \& Pelletier, 2014), including the

${ }^{1}$ Facultad de Ciencias Naturales, Universidad Nacional de la Patagonia "San Juan Bosco". Boulevard Brown 3051 (U9120ACE), Puerto Madryn, Chubut, Argentina. trobbiani@cenpat.edu.ar (corresponding author)

${ }^{2}$ Centro Nacional Patagónico - Consejo Nacional de Investigaciones Científicas y Técnicas (CENPAT - CONICET). Boulevard Brown 2915 (U9120ACD), Puerto Madryn, Chubut, Argentina. leo@cenpat.edu.ar 
assessment of reef fishes (e.g., Willis \& Babcock, 2000; Gardner \& Struthers, 2012; Harvey et al., 2012), sharks (Brooks et al., 2011), deep-water scavengers (Priede et al., 1990, 1994), and epibenthic invertebrates (Stokesbury et al., 2004; Harris \& Stokesbury, 2006); the survey of marine habitats (Koenig et al., 2005; Carbines \& Cole, 2009); and the analysis of behavior in different taxa (e.g., Løkkeborg et al., 1989; Albert et al., 2003), among other uses. A wide variety of camera configurations (from single cameras to stereo-video) were used for these purposes, both mounted onto static tethered or remote frames (baited and non-baited underwater video stations) and attached to mobile devices (remotely operated vehicles or ROVs, sleds and drifting cameras) (Shortis et al., 2009a; Cappo, 2010; Mallet \& Pelletier, 2014). Although the use of underwater video technology for monitoring purposes has recently increased due to the widespread availability of high-definition digital video, these methodologies have still rather limited application (Mallet \& Pelletier, 2014) because of high equipment costs and the need for large vessels and specialized personnel.

Regarding in situ determination of fish lengths, the stereo-video, an array consisting in two synchronized cameras set at fixed relative positions (Harvey \& Shortis, 1996, 1998; Harvey et al., 2002) has allowed accurate and precise estimates of fish size from both static and mobile devices, with mean relative errors $<1 \%$ (Harvey \& Shortis, 1996; Harvey et al., 2001a, 2002). However, reduction in measurement errors comes with increased equipment costs: two cameras with housings and specialized stereophoto software are needed (but some free options for calibrating the cameras are now available, see Bouguet, 2008). Alternatively, a few different configurations based on single cameras attached to baited video stations have been used to estimate fish length (e.g., Priede et al., 1994; Willis \& Babcock, 2000; Stobart et al., 2007; Langlois et al., 2008; Gardner \& Struthers, 2012), but their overall success was hampered by the associated higher errors in size estimates. The most common configuration is a downward-facing camera with the reference scale (in general, two perpendicular marked rods crossing in the middle of the visual field or one scale bar) placed close to the seafloor and the bait holder (Priede et al., 1994; Willis \& Babcock, 2000). Less frequently, horizontal single cameras with one rod fixed at variable distances from the camera, attached to the bait arm, have also been used (Stobart et al., 2007). As an object feigns different sizes depending on its position in relation to the reference scale and the camera lens (see Harvey et al., 2002), only those fishes recorded at the same plane of the rods, perpendicular to the optic axis of the camera, can be measured accurately. Two major disadvantages of single-camera systems are: 1) only a fraction of the fishes that appear within the field of view can be measured, while those passing outside the range of the reference scale have to be excluded; and 2) subjectivity is introduced by the analyst when determining which fishes are close enough to the reference scale to be measured reliably. The placement of several reference scales at different distances from the camera did not help to reduce the errors in size determination which rose to $\sim 60 \%$ (in average) in some BUV designs (e.g., Stobart et al., 2007). Finally, an alternative widely used method relies in different arrays of parallel laser coupled to mobile video cameras, i.e., diver-held or attached to ROV systems (e.g., Love et al., 2000; Rochet et al., 2006; Deakos, 2010), but lasers are less effective in static configurations, as the probability that a fish passes through the laser beams with the correct angle is low (Gledhill et al., 2005).

In this study we introduce the MBUV ("Mirrored Baited Underwater Video"), a novel technique to estimate carnivorous fish size accurately by using a single downwardfacing camera mounted on a tethered baited video station. Our method solves the major constraints of single-camera systems by providing an accurate estimate of the distance between the object to be measured and the reference scale, therefore allowing for a correction of the raw length estimate. In addition, we present the results of a field study aimed at assessing the performance of the MBUV system, and at comparing it with two other methods to measure fish that utilize downward-facing single static cameras.

\section{Material and Methods}

Components of the MBUV system. The MBUV was composed of a $1.8 \mathrm{~m}$ height stainless steel stand (total weight in air, including camera and housing: $42 \mathrm{~kg}$ ), an underwater housing carrying a downward-facing camera, two strained cables holding a bait holder a few centimeters above the bottom, and a structure for protecting the housing. The distinctive and novel feature was the addition of a mirrored surface aimed at estimating the distance between the objects to be measured and the reference scale included in the image (Fig. 1).

One galvanized steel grating $(50 \times 50 \mathrm{~mm}$ grid size $)$ of $\sim 1$ $\mathrm{m}^{2}$ was mounted onto the base of the stand. Four removable OPTIX $^{\mathrm{TM}}$ mirrored acrylic surfaces $(0.20 \times 1.00 \mathrm{~m})$ were fixed to the grating, separated about $\sim 50 \mathrm{~mm}$ between each other for allowing water flux during lowering and rising of the stand. The acrylic surfaces were glued to aluminum plates of the same size to make them rigid (Fig. 1).

We used a Sony DCR-SR300 HDD camcorder into an Equinox Pro-6 underwater housing, mounted onto a horizontal strut fixed at $1.35 \mathrm{~m}$. The optical axis of the camera was perpendicular to the plane of the mirrored surface. A $37 \mathrm{~mm}$ wide-angle lens HD 0.38X (Bower Japan Optics) was added to maximize the bottom area recorded $\left(\sim 3.2 \mathrm{~m}^{2}\right)$. The mirrored surface was centered within it and occupied an area of $\sim 1 \mathrm{~m}^{2}$ (Fig. 1). The camcorder was operated from the surface by a wired remote control (Sony RM-95), which allowed saving disk space and batteries. The deployment was scanned from the surface through a $\mathrm{B} \& \mathrm{~W}$ monitor linked to the camcorder by a coaxial cable. 

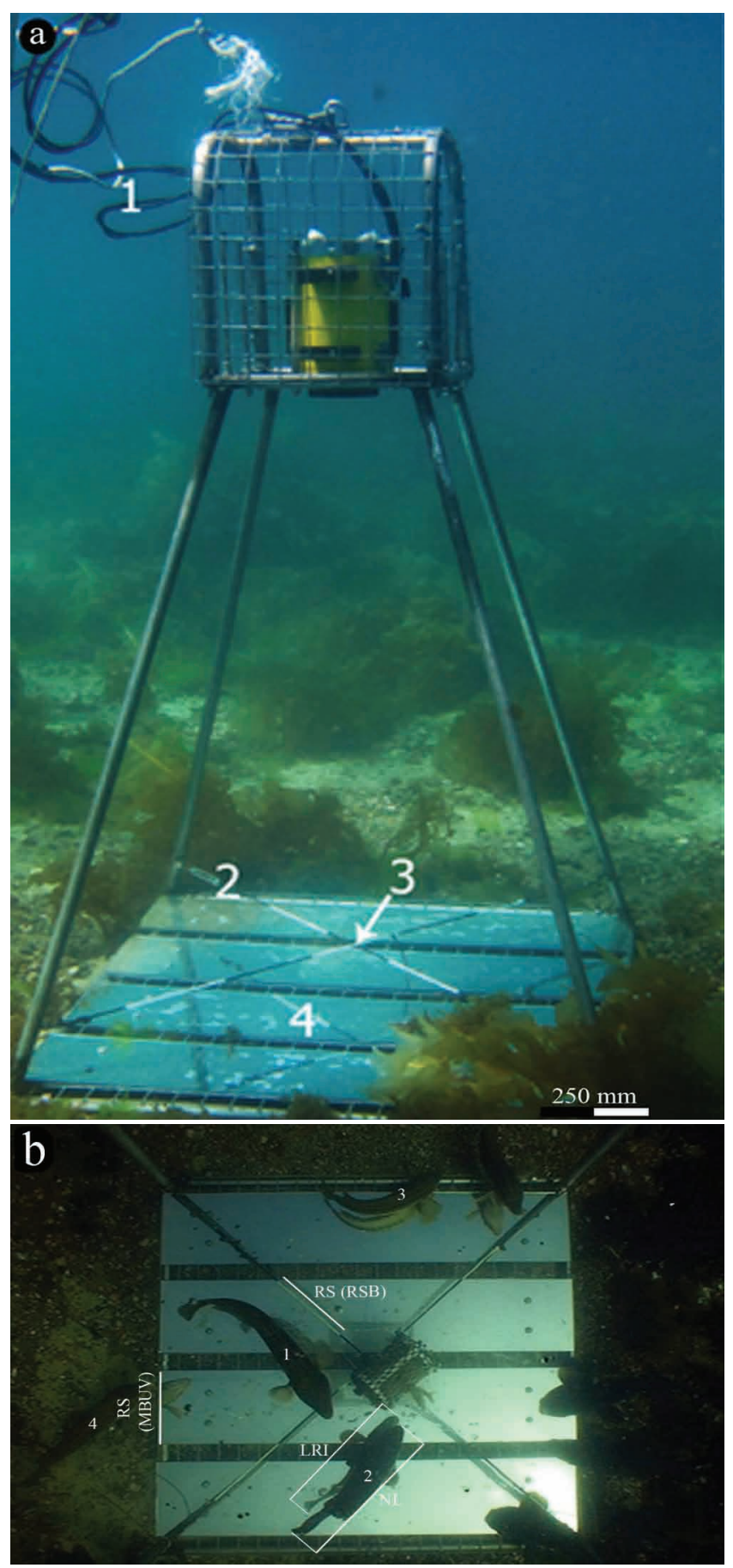

Fig. 1. Mirrored baited underwater video system (MBUV). (a) MBUV settled on bottom for calibration purposes: 1) video signal and remote control, 2) strained cables marked every $200 \mathrm{~mm}$ segments, 3) placement of the bait holder, 4) mirrored surface; (b) Camera view of a MBUV deployment showing the naive length of a sea bass Acanthistius patachonicus (NL), the length of its reflected image (LRI), and the reference scales (RS $=200 \mathrm{~mm}$ ) used for applying the MBUV and Reference scale at the bait level (RSB) procedures. Four fishes (1-4) could be accurately measured in this snapshot; fish \#4 could be sized even when its body laid wholly outside of the mirrored area but was partially reflected by it.
The bait holder was a cylinder of $90 \mathrm{~mm}$ in diameter made of PVC and covered by fishing net, placed in the center of the image. The cables supporting the bait holder were marked every $200 \mathrm{~mm}$ segments with contrasting color tape; they were $109 \mathrm{~mm}$ above the mirrored surface.

System calibration. In order to obtain accurate length estimates, the naive estimate (i.e., the estimate obtained by measuring an object as if both the object and the reference scale were on the same plane) has to be scaled down by a factor (hereafter, correction factor CF) that changes with distance between the object and the reference scale, and relative position with respect to the camera. The mirrored surface allowed CF to be calculated as a function of the ratio between the naive length of the object, NL, and the length of its reflected image, LRI (i.e., NL/LRI ratio) (Fig. 1b) for any distance between the object and the reference scale. To calibrate the system, we conducted a controlled experiment and used the following expression to estimate the real length (RL) of the target:

$$
R L=\frac{N L}{C F}(1)
$$

Experimental procedure and data acquisition. The empirical calibration of the optic system was made in the field at 5-6 m depth. A polystyrene sphere $(117 \mathrm{~mm}$ diameter) was filmed while being moved by a scuba diver haphazardly in planes perpendicular to the optic axis of the camera, at 22 different controlled heights from the mirrored surface, between 110 (the base of the sphere was actually $52 \mathrm{~mm}$ above the mirror) and $950 \mathrm{~mm}$ (at greater distances from the mirror the sphere covered the visual field almost completely). A series of 122 snapshots were taken from the videos by using the software Picture Motion Browser. The number of snapshots with the sphere at the same height occupying different areas within the field of view ranged between 2 and $9($ mode $=4)$. Barrel distortion was removed from the images prior to taking measures by processing the snapshots with the software PTLens. Optical distortion was corrected manually by changing the distortion parameter until removal of the barrel effect, and the correction was applied to all the snapshots. The diameter of the sphere, indicated by a black line painted around its perimeter, and the length of the corresponding reflection were determined with the free software ImageJ. The smaller side of one of the mirrors $(200 \mathrm{~mm})$ was used to scale the images (Fig. 1b).

Function fitting. Two linear functions were fitted to the NL/LRI ratio calculated from the polystyrene sphere measurements. The first of these was the calibration function used to estimate CF. Another function, used to compare the performance of the MBUV with other methods (e.g., Priede et al., 1994; Willis \& Babcock, 2000; King et al., 2006; Gardner \& Struthers, 2012), allowed estimating 
the distance of a given object to the reference scale included in the image (hereafter referred as 'Height' model). For the calibration model, CF was regressed on the NL/LRI ratio. As the inspection of the raw data suggested heterogeneous variance for this model, a quasi error structure and identity link was used to evaluate different variance functions. For the 'Height' model, a polynomial function was fitted to the reciprocal of the NL/LRI ratio. As maximum accuracy was desired, we selected the polynomial of highest degree for which all terms differed significantly from zero. Plots of standardized residuals against fitted values were used for selecting the most appropriate variance function in the calibration model, and for checking the selected error structure in the 'Height' model and homoscedasticity in both models. To coerce the calibration function to go through the point $(1,1)$ (i.e., $\mathrm{NL}=\mathrm{LRI}$ for an object placed on the same plane of the mirrored surface, which served also as the reference scale), we added this point to the data series and gave it a weight 100 times greater than all the other points. Likewise, the 'Height' function was forced to go through the point $(1,0)$ for the same reason. The models were fitted using the $g l m$ function of the package 'stats' included in the R software (R Development Core Team, 2012).

Accuracy and precision of length measures. We used a field experiment to test the accuracy and precision of the length estimates obtained by the MBUV. Three plastic silhouettes of $112 \mathrm{~mm}, 360 \mathrm{~mm}$ and $444 \mathrm{~mm}$ were haphazardly moved by a scuba diver throughout the field of view. Care was taken to ensure that the silhouettes were in a horizontal position, perpendicular to the optical axis of the camera, since a reduction in that angle can affect the length estimation (Harvey et al., 2002).

For comparison with published results, the accuracy of length estimates was evaluated through the mean relative error:

$$
\text { Mean relative error }=\text { mean }\left(\frac{\hat{\lambda}_{k m}-\lambda_{m}}{\lambda_{m}}\right)(2)
$$

where $\hat{\lambda}_{k m}$ is the $k$-th length estimate for the plastic silhouette $m$, and $\lambda_{m}$ is the real length of the object $m$. The precision of the length estimates was evaluated by the coefficients of variation $\left(\mathrm{CV}_{m}\right)$, based on the $k$ estimates for each silhouette $m$, which were at different distances (not controlled) from the reference scale (as recommended by Thresher \& Gunn, 1986).

\section{Case study}

Study area and rocky reef fishes. Subtidal rocky reefs within the northern Patagonian gulfs of Argentina are formed by isolated small rocky outcrops that most commonly extend between $>50 \mathrm{~m}$ and a few hundred meters on an otherwise flat, soft bottom. Most of those reefs are linear structures, typically low breaks or ledges (from 0.2 to $1.5 \mathrm{~m}$ high) formed along the edge of submerged abrasion limestone platforms, where cavities are formed. Four natural (A - D) and one artificial (E: "Albatros" shipwreck) Submarine Parks located

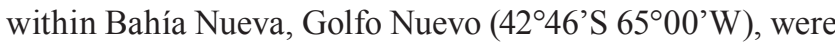
used for testing the performance of the MBUV.

The rocky reef fish assemblage that inhabits the northern Patagonian reefs is composed by about 29 species, but only four are abundant or very common within Golfo Nuevo, all of them carnivorous reef-dweller fishes (Galván et al., 2009a, 2009b). To evaluate the performance of the MBUV we selected the Argentine sea bass Acanthistius patachonicus (Jenyns, 1840) (Serranidae), an euryphagous predator that reaches up to $65 \mathrm{~cm}$ total length (TL) (Irigoyen et al., 2008; Galván et al., 2009a). This species is the most abundant in the reefs, particularly during late summer and early fall (Galván et al., 2009b; Irigoyen et al., 2013).

Sampling design and field operation. Fieldwork was conducted onboard R/V "CENPAT I", a $7.8 \mathrm{~m}$ cabin boat with a 115 HP outboard motor. The MBUV was deployed between 06 March and 10 April 2012 between 5-20 m depths: three times in reefs $\mathrm{A}-\mathrm{C}$, twice in reef $\mathrm{D}$, and once in the artificial reef $\mathrm{E}$. Recordings were conducted between 10:00 - 16:00 $\mathrm{h}$ to avoid any bias related to possible changes in fish behavior throughout the day (Willis \& Babcock, 2000; Thompson \& Mapstone, 2002). Within each reef, successive deployments were separated by at least $25 \mathrm{~m}$ (horizontal water visibility ranged between $6-11 \mathrm{~m}$ ).

Deployment time was fixed at $15 \mathrm{~min}$ (total recorded time $=3 \mathrm{~h}$ ). The MBUV was baited with a frozen compact pill ( $\sim 250$ g weight) containing chopped silverside, bonito oil, and cornmeal. Tentacles of squid were attached externally to the bait holder to increase fish attraction. Fish were immediately attracted to the bait holder so that the camera started to record as soon as it reached the bottom.

Data acquisition. To maximize the number of measured fish while avoiding repeated measures of the same individuals, we identified the snapshots with the larger number of fish reflected by the mirrored surface (see Schobernd et al., 2014 for a discussion on this topic). Videos were scrutinized frame by frame from a few seconds previous to a few seconds after of each selected frames, and new fish entering the mirrored area in that time period was also measured. For each deployment we used the video section from which the largest number of distinct individuals could be measured following the explained procedure. To increase the accuracy of length measurements, we chose the "best" frame for each fish (i.e., fish were straighter and parallel to the bottom). For each individual, the length between the tip of the snout and the extreme of the caudal fin was measured, both onto the fish and on its reflected image. When the reflection was incomplete the distance between two distinguishable points were used to estimate the NL/LRI ratio.

We used the same selected video sections and applied the RSB method (Priede et al., 1994; Willis \& Babcock, 2000; King et al., 2006, 2008) for comparison purposes. 
In this case, only those fish passing through the field of view approximately at the level of the reference scale were measured. The strained cables supporting the bait holder served as the size reference to scale the images (Fig. 1b). All fish far from the bait holder, or clearly above or below its level were disregarded.

Length frequency distributions of fish in reefs A - E were obtained by pooling data from all the deployments made in the same reef.

Comparison of the MBUV with other single camera methods. To evaluate the performance of the MBUV we used scatter plots with length estimates and the naive and RSB estimates, respectively. We also compared the number of fish measured by the MBUV with respect to the RSB using a Wilcoxon signed-rank test. Statistical analysis was performed with the wilcox.test function of the package 'stats' included in the R software (R Development Core Team, 2012).

Finally, to evaluate the performance of the analyst when selecting which fish were closed enough to be reliably measured with the RSB method, and quantify the problem of subjectivity introduced by that technique, we used the 'Height' function to estimate the distance between the mirrored surface and those fish.

Abbreviations list. B\&W: Black \& White; BUV: Baited Underwater Video; CF: Correction factor; LRI: Length of the target's reflected image; MBUV: Mirrored Baited Underwater Video; NL: Naive length of the target; PVC: Polyvinyl chloride; RL: Real length of the target; ROV: Remotely operated vehicle; RSB: Reference scale at the bait level; TL: Total length.

\section{Results}

System calibration, accuracy and precision. The correction factor increased linearly with the polystyrene sphere getting closer to the camera (Fig. 2a). This model explained $99.6 \%$ of the total deviance. The best model for the 'Height' function was a cubic polynomial of the NL/LRI ratio $^{-1}$ that explained $99.6 \%$ of the total deviance (Fig. $2 b$ ).

Our method allowed estimating the sizes of the three plastic silhouettes with accuracy and precision, but a slight tendency to underestimation was evident (Fig. 3). Among 84 snapshots extracted from the calibration video, 44 of them belonged to the silhouette of $112 \mathrm{~mm}, 35$ to that of $360 \mathrm{~mm}$, and the remaining 5 to the silhouette of $444 \mathrm{~mm}$. The mean relative error was $-0.6 \%$ (quartiles $25 \%$ and $75 \%$ : $-3.2 \%$ and $1.1 \%$, respectively). The largest relative errors rounded $\pm 10 \%$. Size estimates were also precise: mean CV was $3.3 \%$, and ranged between $2.3 \%$ and $4.8 \%$ for the largest $(444 \mathrm{~mm})$ and smallest $(112 \mathrm{~mm})$ silhouettes, respectively. The height range estimated for the plastic silhouettes was $165 \mathrm{~mm}-756 \mathrm{~mm}$ (taken from the mirrored surface), with quartiles $25 \%=289 \mathrm{~mm}$ and $75 \%=515 \mathrm{~mm}$.
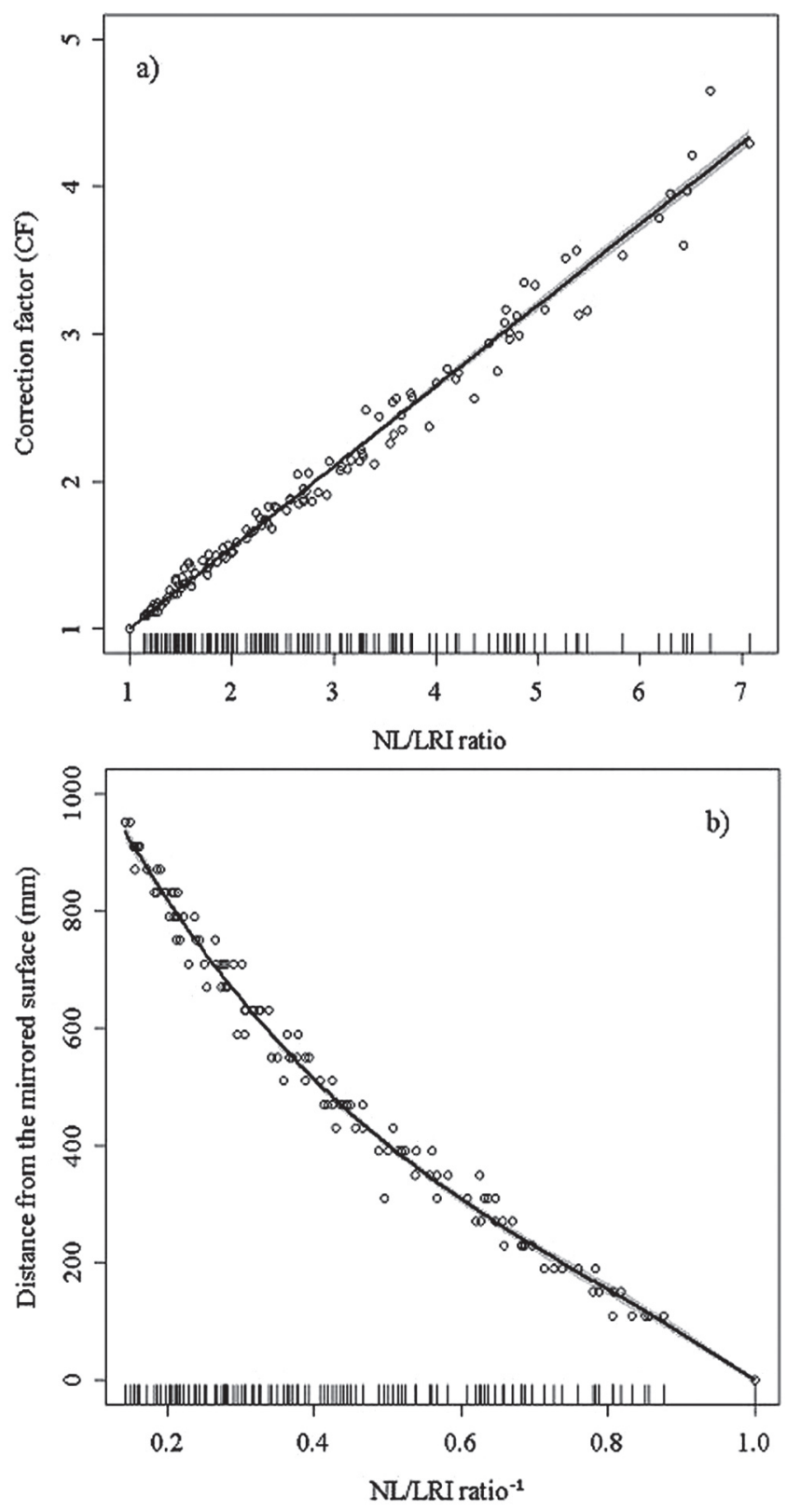

Fig. 2. Calibration (a) and 'Height' (b) functions for the Mirrored baited underwater video system (MBUV) system. The solid lines represent the fitted models. Shaded areas represent $95 \%$ confidence regions. Jittered rugs on the $\mathrm{x}$-axis indicate the distribution of the NL/LRI ratio and NL/LRI ratio $^{-1}$ data, respectively. $\mathrm{NL}=$ naive length, $\mathrm{LRI}=$ length of the reflected image.

Performance assessment in the field. The MBUV attracted the four most conspicuous and abundant species in the assemblage: Pseudopercis semifasciata and Pinguipes brasilianus (Pinguipedidae), Sebastes oculatus (Sebastidae), and A. patachonicus (Video S1, available as Supplementary Material at www.scielo.br/ni). The latter was the most abundant fish in the surveyed reefs and was attracted by the bait in almost all deployments, except for one in which no fishes were recorded. 


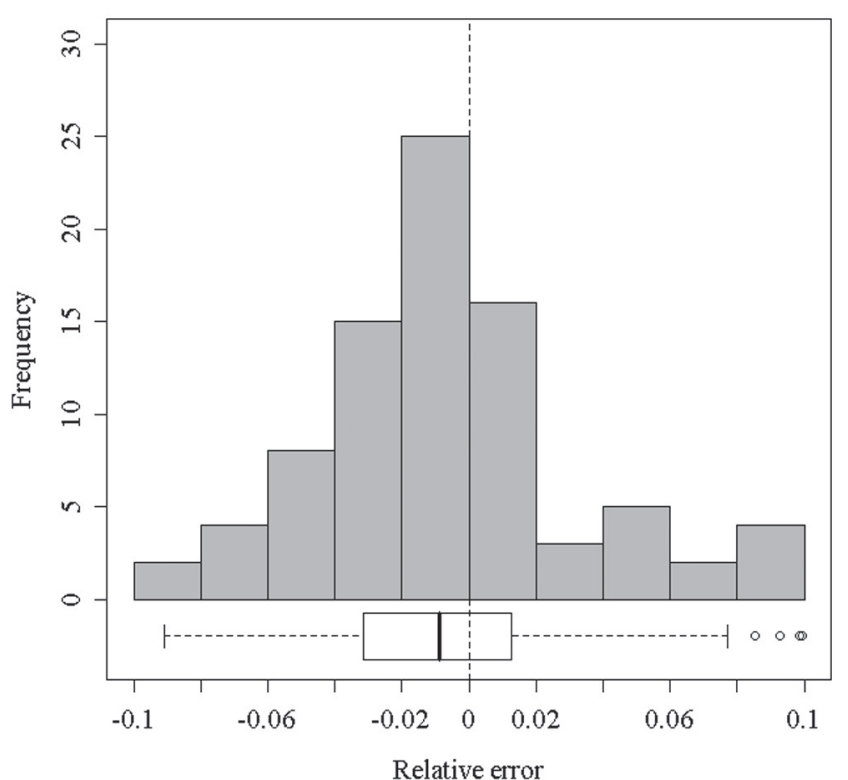

Fig. 3. Histogram and boxplot showing the distribution of the relative errors of length estimates for three plastic silhouettes of $112 \mathrm{~mm}, 360 \mathrm{~mm}$ and $444 \mathrm{~mm}$. The boxplot below indicates a median relative error $=-0.9 \%$.

The maximum number of $A$. patachonicus within the field of view was reached $11-12$ min after deployment. The largest number of fish simultaneously occupying the mirrored area at least partially and able to be measured in the same snapshot was between 4 and 17 individuals (total $n=112$ ). The number of fish that appeared within the entire field of view ranged between 5 and $25(n=174)$. Scrutinizing the videos a few frames before and after the scene containing the largest number of fish allowed to raise the number of individuals measured to 132. Some fish could not be measured because they were partially covered by other fishes, were not completely within the field of view or were not reflected at least partially by the mirrored area.

Length ranges of fish were similar in different reefs except for reef $\mathrm{B}$, in which a larger abundance of smaller sea basses was recorded (Fig. 4). Overall, fish approached the bait close to the holder level; the maximum height estimated for $A$. patachonicus was $541 \mathrm{~mm}$ (quartiles 25\% and $75 \%=70 \mathrm{~mm}$ and $195 \mathrm{~mm}$, respectively).

Comparison with other single-camera methods. Overall, the length distributions obtained for each reef depended on the method used (Figs. 4-5). The naive estimates clearly overestimated fish size, while the RSB estimates were intermediate between the lengths obtained with the naive and MBUV methods.

MBUV versus naive estimation. Although most fish (78\%) were less than $200 \mathrm{~mm}$ from the reference scale, the naive method overestimated significantly the length of 106 fish (of 132 ), between $>5 \%$ and $91 \%$, with respect to the values obtained with the MBUV (Fig. 5a). In turn, maximum TL obtained with both methods was $429 \mathrm{~mm}$ and $795 \mathrm{~mm}$ (naive estimate); the latter far beyond the maximum length recorded for A. patachonicus (i.e., $650 \mathrm{~mm}$ TL: Irigoyen et al., 2008).

MBUV versus RSB. The MBUV approach resulted in more fish measurements (132 versus 98), although the difference in the number of individuals measured with both methods was non significant $\left(\mathrm{V}\right.$ statistic $=15 ; P\left[n_{\mathrm{MBUV}}=\right.$ $\left.\left.n_{\mathrm{RSB}}\right]=0.06\right)$. Overall, the RSB length distributions for each reef were more similar to those obtained with the MBUV than the naive estimates, particularly in reefs A, $\mathrm{B}$ and $\mathrm{E}$, in which the number of fish measured with the RSB method was larger (27, 14 and 24, respectively) (Fig. 4). When comparing the lengths of the same subset of fish measured with both methods, 26 individuals (39\% of 67 fish) measured with RSB differed by more than $5 \%$ relative to the MBUV estimate (Fig. 5b). Of these, all but one had larger measurements using the RSB method. The analyst included 11 fish placed $>90 \mathrm{~mm}$ above the marked cables (i.e., even higher than the top level of the bait holder), which led to overestimate their length up to 33\% (Fig. S2, available as Supplementary Material, only in the on line version).

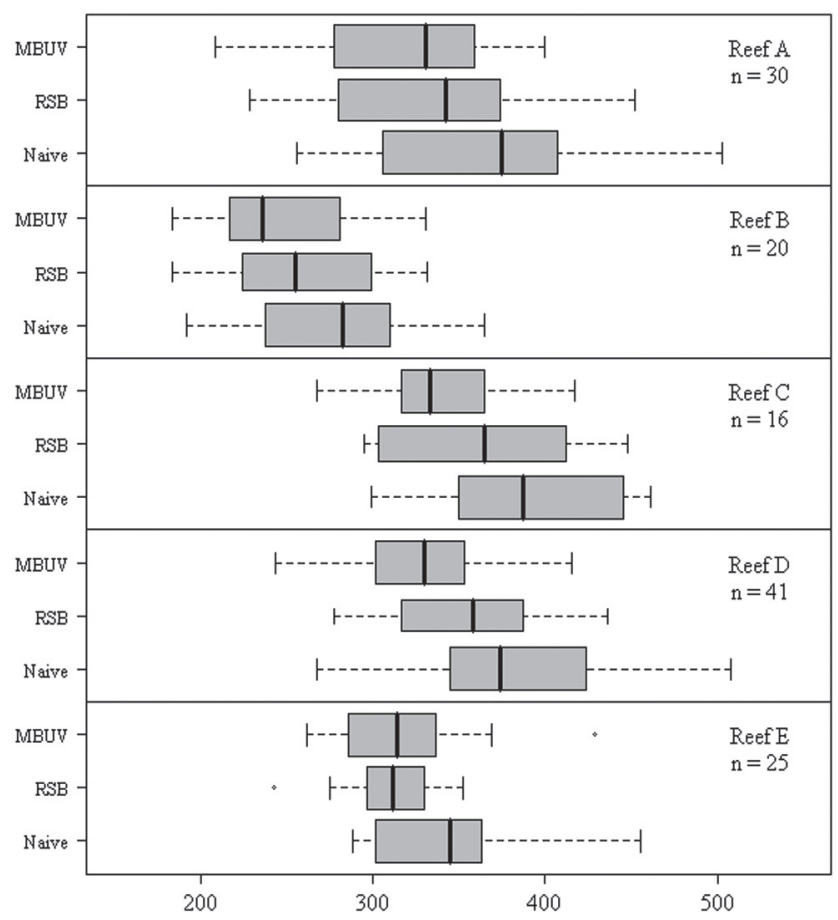

Fig. 4. Boxplots showing the length distributions ( $\mathrm{mm}$ ) for Acanthistius patachonicus in five Submarine Parks within Golfo Nuevo, estimated by the naive $(n=132)$, Reference scale at the bait level (RSB) $(n=98)$ and Mirrored baited underwater video system (MBUV) $(n=132)$ methods. The numbers of fish measured with the MBUV in each reef are indicated, and the widths of the boxes within each reef are proportional to those numbers. The $\mathrm{x}$-axis was truncated to avoid loss of detail. 

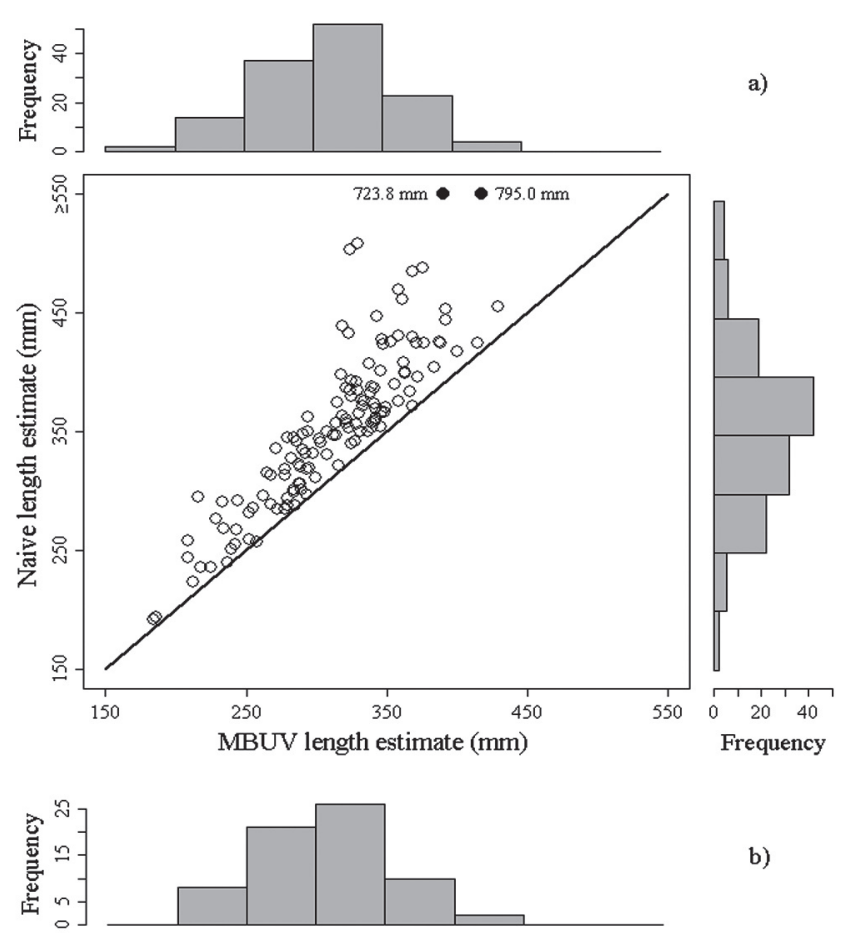

b)

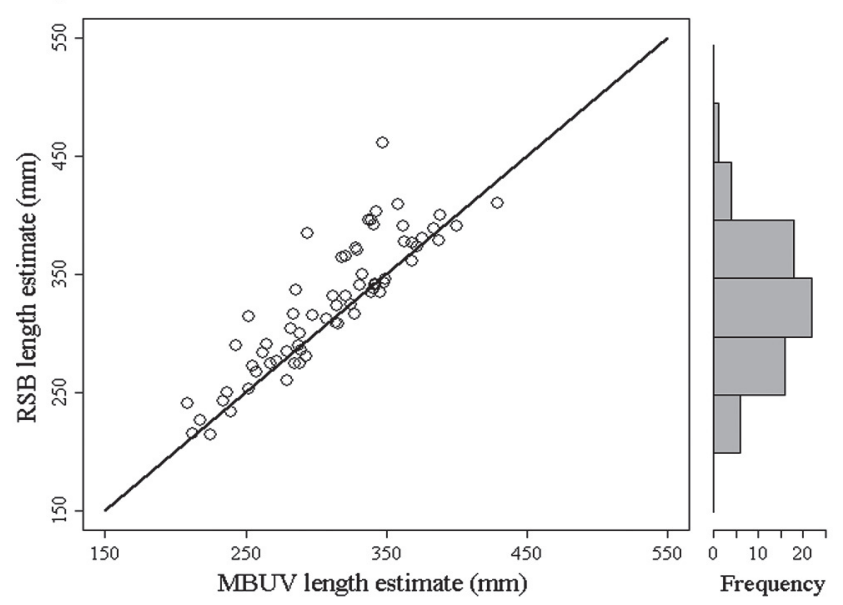

Fig. 5. Scatter plots with marginal histograms showing fish length estimates ( $\mathrm{mm}$ ) obtained with (a) Mirrored baited underwater video system (MBUV) and naive methods (n =132), and with (b) MBUV and Reference scale at the bait level (RSB) methods $(n=67)$, in five Submarine Parks within Golfo Nuevo. Solid circles in (a) represent truncated lengths $(>550 \mathrm{~mm})$. The corresponding naive estimates for the truncated lengths are indicated next to the circles. Solid black lines represent the regression 1:1 in both boxes.

\section{Discussion}

In this paper we present the MBUV, an efficient and simple method for estimating carnivorous fish size accurately and precisely from a single static camera. The evaluation of the MBUV performance allowed us to highlight some limitations of the RSB systems, and quantify the error in size estimates due to the analyst subjective decision about which individuals can be reliably measured.
In our field application the MBUV attracted the four most common and conspicuous carnivorous species of the northern Patagonia rocky reef fish assemblage, also targeted by anglers and hand-liners. However, small cryptic fishes, also common in the reefs surveyed, like Ribeiroclinus eigenmanni (Jordan, 1888) (Clinidae) and Helcogrammoides cunninghami (Smitt, 1898) (Tripterygiidae), were not recorded. This agrees with what was observed in others systems, in which baited video stations, particularly bearing vertical downward-facing cameras, underestimated the species richness recorded by underwater visual censuses, attracting proportionally most mobile predatory species than cave dweller, small and cryptic fishes (Watson et al., 2005; Langlois et al., 2006; Colton \& Swearer, 2010).

The MBUV was inspired on a similar principle originally suggested by Bailey et al. (2007), according to which the position of the shadows of benthopelagic fishes over the bottom, illuminated from above, would be useful to estimate the location of fishes in the water column, which in turn could be used for adjusting their length estimates. However, in contrast to the MBUV system, the accuracy of the shadow technique drastically reduced as animals moved further from the seabed (Bailey et al., 2007).

Although an analytical solution for estimating fish height over the mirrored area could be available, we suggest a straightforward empirical calibration procedure aiming at increasing its versatility, as the customization of the MBUV to cover particular needs could drastically modify the characteristics of the optical system.

A few horizontal single camera configurations mounted on BUV stations, used to estimate fish length, were reported in the literature, but overall they performed poorly. Stobart et al. (2007), for example, added three $0.5 \mathrm{~m}$ rods delimiting three fish measuring zones along the bait arm, at 0.5, 1 and $2 \mathrm{~m}$ distances from the camera. These authors reported length estimates with mean relative errors between $55 \%$ for objects located within $1 \mathrm{~m}$ from the camera, and 59\% for objects within the closest $0.5 \mathrm{~m}$ segment. Their mean CV was $3.3 \%$, but, different from our study, CVs in Stobart et al. (2007) seem to have been estimated based on repeated measures of objects set at fixed distances from the camera. Brooks et al. (2011) discarded the use of a horizontal BUV to estimate shark length because the conditions to obtain a reliable measure (i.e., the entire shark had to be visible in the frame, parallel to the scale bar and no more than $1 \mathrm{~m}$ behind it) were seldom met.

RSB systems equipped with downward-facing cameras were more effective at measuring fishes from video recordings. However, individuals above or behind the reference scales had to be disregarded. Priede et al. (1994) pioneered the use of RSB arrangements to estimate fish length from baited stations. In their design there was a short space between the bottom and the reference scale, so fishes could swim or rest a few centimeters behind it (Priede et al., 1994). As only those fishes at the level of, or behind, the reference scale were measured, errors were more likely 
underestimates of fish length (King et al., 2006, 2008). In other cases the frame, which rested on the seabed, was directly marked to provide a reference scale, so fish size was most probably overestimated (Willis \& Babcock, 2000). In addition to the original RSB arrangements, Langlois et al. (2008) presented a suspended downward-facing BUV with single camera configuration aimed to overcome the limitations of benthic BUV systems, designed specifically to be used in topographically complex or in kelp forest habitats. In the suspended BUV, the bait holder and the reference scale were both maintained $150 \mathrm{~cm}$ over the bottom by a pressure buoy from which the whole system was attached; hence fishes could be recorded clearly above or behind the scale bar. In all of those configurations, errors in length estimates strongly depended on fishes' behavior: while some species approached the bait at the level of the bait holder or even above it, others rested on the bottom, or swam underneath the bait. These limitations were outperformed with the MBUV, which was less influenced by fish behavior as it allowed estimating the length of an object independently of its distance to the reference scale. Subjectivity was also reduced in the measuring process, as the analyst does not have to decide which fishes to measure. With respect to the accuracy and precision, its mean values were even in the range obtained by stereo-video techniques (mean relative error: $-0.6 \%$ for the MBUV and $<1 \%$ for stereo-video, and mean CV: $3.3 \%$ for the MBUV and $2.0 \%-2.6 \%$ for stereovideo, see Harvey \& Shortis, 1996; Harvey et al., 2001a, 2002; Shortis et al. 2009b). Nonetheless, it should be noted that the accuracy values that we provide as a reference for the MBUV are the greatest, since the silhouettes of known size that we used to evaluate its performance were rigid and maintained perpendicular to the optic axis. Although single camera systems are more sensitive than stereo-video to changes in subject orientation (Harvey et al., 2002), in downward-facing configurations fishes usually pass through the field of view rather perpendicular to the optic axis of the camera. Despite this, fish passing through the mirrored surface obliquely to the bottom should be disregarded to avoid underestimating their sizes. Finally, to be measured with the MBUV, fishes need to enter the mirrored area at least partially. Once two distinguishable landmarks are identified both on the body of the fish recorded and on its reflection, individuals approaching the bait holder but not entirely within the mirrored surface can also be measured, which extends the useful measuring area considerably, far beyond the central $\sim 1 \mathrm{~m}^{2}$ mirrored area within the field of view (Fig. 1). Although A. patachonicus is a medium-sized species and we measured larger fish compared with data obtained with the parallel laser technique in the same reefs (data not showed), the occurrence of potential bias towards smaller size classes in larger species (i.e., $>1 \mathrm{~m}$ long) should be further investigated.

The use of a mirrored surface for sizing a coral reef fish was first achieved by Pfister \& Goulet (1999), who took advantage of the territorial behavior (i.e., parallel swimming) of anemonefish Amphiprion bicinctus (Rüppell, 1830) (Pomacentridae) when a mirror was put between them and their host anemone. Neither such behavior nor other agonistic displays were observed during the MBUV deployments. Moreover, the location of the mirrored surface, below the fishes, seemed not to elicit any particular behavioral display, and more than half of the individuals in the selected snapshots $(\sim 57 \%)$ had at least part of their trunk onto the mirrored surface, within a circular area of $50 \mathrm{~cm}$ radio with center in the bait holder (Fig. S3 available as Supplementary Material, only in the on line version). Nevertheless, further experiments aiming at comparing the abundance of fish with and without the mirror area would be desirable before the implementation of the MBUV as a regular monitoring tool.

The MBUV have the same overall limitations of other downward-facing BUV systems, mainly: carnivorous fishes directly attracted to the bait are preferentially recorded; temperate and subtropical/tropical species may react differently to the bait; smaller fishes can be out competed by larger individuals (Stoner, 2004); they are of limited use on irregular bottoms or during rough weather; the area sampled is reduced and hence can be rapidly saturated as the number of fish in the field of view increases; the size of fish swimming obliquely to the bottom may be underestimated; and some difficulties may arise when trying to identify fishes from the dorsal side (see Langlois et al., 2006; Wraith, 2007; Cappo, 2010 for further discussion on the disadvantages of downward-facing BUVs). Nevertheless, it proved to be useful for monitoring temperate carnivorous rocky-reef fishes (e.g., Willis et al., 2000; this study). In New Zealand, for example, downward-facing BUVs have prevailed over horizontal BUVs and were incorporated by several long term monitoring programs aimed at assessing the abundance and length distributions of carnivorous species (Langlois et al., 2008; Roux De Buisson, 2010; Gardner \& Struthers, 2012; Morrison \& Gregor, 2012). Although by no means we claim the MBUV can replace more robust and versatile horizontal stereo-video systems or underwater visual censuses in shallow waters for assessing the species composition, relative abundance or size structure of fishes, its inexpensiveness and simplicity makes it an attractive alternative for low-cost sizing of carnivorous species attracted by the bait in topographically simple habitats, that can be used as ecological indicators of the reefs state.

The results presented here are species and system specific; they should not be extrapolated to other fishes without prior experimentation because different species might respond differently to the bait and the presence of the MBUV. Admittedly, the naive estimation is not a valid approach and it was solely explored to evaluate the extent of overestimation it produces. Surprisingly, significantly different length distributions were obtained despite most fish (78\%) being only $200 \mathrm{~mm}$ or less off the reference scale. Although the RSB measures were closer to the MBUV estimates than the naive ones (Fig. 5b), the method allowed 
measuring $26 \%$ less fish, and $\sim 40 \%$ of the lengths obtained differed by more than 5\% compared with the MBUV estimates (they were mostly overestimates, originated by the subjectivity introduced by the analyst when deciding which fish are close enough to the reference scale to be reliably measured). Other authors applying the RSB method reported errors that reached $\sim 10 \%$ in length for fishes that in general rested on the bottom, at the level of the reference scale, which is an ideal situation (Willis \& Babcock, 2000). Finally, despite measuring fish with the MBUV implies that two distances have to be taken for each fish, in average, the number of fish measured per man-hour with the MBUV and RSB were almost equal, because most of the laboratory time was spent in scrutinizing the videos to find the frames with larger fish abundances.

\section{Acknowledgments}

We thank Daniel Remenar, Néstor Ortiz, Ricardo Vera, Fabián Quiroga, Pablo Alvarez, Mariangeles López, and the staff from Aquatours Buceo for their help during fieldwork. "Hormiga" Díaz constructed the stand and Ing. Jorge Dignani helped us with the electronic devices. Pedro Fiorda contributed with R codes. R code for Fig. 7 was based on one published by K. Kleinman and N. Horton in SAS and R (http://sas-and-r.blogspot.com.ar). Stephanie Stephansky and Ana Parma helped with the English language. Miguel Pascual, Andrés Rivas, Silvina Van der Molen, Noela Sánchez Carnero, Daniel Rodríguez, Martín García Asorey, Ana Parma, and two anonymous reviewers made useful comments on an earlier version of the article. This work was supported by grants from Consejo Nacional de Investigaciones Científicas y Técnicas (PIP 2010-2012), Agencia Nacional de Promoción Científica y Tecnológica (PICT 2006-1468) (both granted to LAV), and Idea Wild (granted to GAT), and constitutes a substantial part of the BSc. Thesis of GAT.

\section{References}

Albert, O. T., A. Harbitz \& A. S. Høines. 2003. Greenland halibut observed by video in front of survey trawl: behaviour, escapement, and spatial pattern. Journal of Sea Research, 50: 117-127.

Bailey, D. M., N. J. King \& I. G. Priede. 2007. Cameras and carcasses: historical and current methods for using artificial food falls to study deep-water animals. Marine Ecology Progress Series, 350: 179-191.

Bouguet, J. Y. 2008. Camera calibration toolbox for Matlab [online]. Available from: http://vision.caltech.edu/bouguetj/calib_doc/ index.html (Jan. 2014).

Brooks, E. J., K. A. Sloman, D. W. Sims \& A. J. Danylchuk. 2011. Validating the use of baited remote underwater video surveys for assessing the diversity, distribution and abundance of sharks in the Bahamas. Endangered Species Research, 13: 231-243.

Cappo, M. C. 2010. Development of a baited video technique and spatial models to explain patterns of fish biodiversity in interreef waters. Unpublished Ph.D. Dissertation, James Cook University, Townsville, 246p.
Carbines, G. \& R. G. Cole. 2009. Using a remote drift underwater video (DUV) to examine dredge impacts on demersal fishes and benthic habitat complexity in Foveaux Strait, Southern New Zealand. Fisheries Research, 96: 230-237.

Colton, M. \& S. Swearer. 2010. A comparison of two survey methods: differences between underwater visual census and baited remote underwater video. Marine Ecology Progress Series, 400: 19-36.

Deakos, M. H. 2010. Paired-laser photogrammetry as a simple and accurate system for measuring the body size of free-ranging manta rays Manta alfredi. Aquatic Biology, 10: 1-10.

Galván, D. E., F. Botto, A. M. Parma, L. Bandieri, N. Mohamed \& O. O. Iribarne. 2009a. Food partitioning and spatial subsidy in shelter-limited fishes inhabiting patchy reefs of Patagonia. Journal of Fish Biology, 75: 2585-2605.

Galván, D. E., L. A. Venerus \& A. J. Irigoyen. 2009b. The reeffish fauna of the Northern Patagonian gulfs of Argentina, Southwestern Atlantic. The Open Fish Science Journal, 2: 90-98.

Gardner, J. P. A. \& C. D. Struthers. 2012. Comparisons among survey methodologies to test for abundance and size of a highly targeted fish species. Journal of Fish Biology, 82: 242-262.

Gledhill, C. T., G. W. Ingram, Jr., K. R. Rademacher, P. Felts \& B. Trigg. 2005. SEDAR10-DW12 NOAA Fisheries Reef Fish Video Surveys: yearly indices of abundance for gag (Mycteroperca microlepis) - SEDAR SouthEast Data, Assessment, \& Review. Gulf of Mexico Gag Grouper Stock Assessment Report. SECTION 2. http://www.sefsc.noaa. gov/sedar/download/S10DW12\%20videoSurvey\%20GOM. pdf?id=DOCUMENT (25 Feb. 2015).

Harris, B. P. \& K. D. E. Stokesbury. 2006. Shell growth of sea scallops (Placopecten magellanicus) in the southern and northern Great South Channel, USA. ICES Journal of Marine Science, 63: 811-821.

Harvey, E. S., S. R. Dorman, C. Fitzpatrick, S. J. Newman \& D. L. McLean. 2012. Response of diurnal and nocturnal coral reef fish to protection from fishing: an assessment using baited remote underwater video. Coral Reefs, 31: 939-950.

Harvey, E. S., D. Fletcher \& M. R. Shortis. 2001a. A comparison of the precision and accuracy of estimates of reef-fish lengths determined visually by divers with estimates produced by a stereo-video system. Fishery Bulletin, 99: 63-71.

Harvey, E. S., D. Fletcher \& M. R. Shortis. 2001b. Improving the statistical power of length estimates of reef fish: a comparison of estimates determined visually by divers with estimates produced by a stereo-video system. Fishery Bulletin, 99: 72-80.

Harvey, E. S. \& M. R. Shortis. 1996. A system for stereo-video measurement of subtidal organisms. Marine Technology Society Journal, 29: 10-22.

Harvey, E. S. \& M. R. Shortis. 1998. Calibration stability of an underwater stereo-video system: implications for measurement accuracy and precision. Marine Technology Society Journal, 32: 3-17.

Harvey, E. S., M. R. Shortis, M. Stadler \& M. Cappo. 2002. A comparison of the accuracy and precision of measurements from single and stereo-video systems. Marine Technology Society Journal, 36: 38-49.

Irigoyen, A. J., L. Cavaleri Gerhardinger \& A. Carvalho-Filho. 2008. On the status of the species of Acanthistius (Gill, 1862) (Percoidei) in the South-West Atlantic Ocean. Zootaxa, 1813: 51-59. 
Irigoyen, A. J., D. E. Galván, L. A. Venerus \& A. M. Parma. 2013. Variability in abundance of temperate reef fishes estimated by visual census. PLoS ONE, 8: e61072.

King, N. J., P. M. Bagley \& I. G. Priede. 2006. Depth zonation and latitudinal distribution of deep-sea scavenging demersal fishes of the Mid-Atlantic Ridge, 42 to $53^{\circ} \mathrm{N}$. Marine Ecology Progress Series, 319: 263-274.

King, N. J., A. J. Jamieson, P. M. Bagley, P. M. \& I. G. Priede. 2008. Deep-sea scavenging demersal fish fauna of the Nazaré Canyon system, Iberian coast, north-east Atlantic Ocean. Journal of Fish Biology, 72: 1804-1814.

Koenig, C. C., A. N. Shepard, J. K. Reed, F. C. Coleman, S. D. Brooke, J. Brusher \& K. M. Scanlon. 2005. Habitat and fish populations in the deep-sea Oculina coral ecosystem of the Western Atlantic. American Fisheries Society Symposium, 41: 795-805.

Langlois, T. J., M. J. Anderson \& P. Buisson. 2008. Baited Underwater Video: Comparison of a Benthic Versus a Suspended System. Unpublished Report prepared for Northland Conservancy, Department of Conservation, Auckland Uniservices Ltd, The University of Auckland.

Langlois, T. J., P. Chabanet, D. Pelletier \& E. S. Harvey. 2006. Baited underwater video for assessing reef fish populations in Marine Reserves. SPC Fisheries Newsletter, 118: 53-57.

Løkkeborg, S., A. Bjordal \& A. Fernö. 1989. Responses of cod (Gadus morhua) and haddock (Melanogrammus aeglefinus) to baited hooks in the natural environment. Canadian Journal of Fisheries and Aquatic Sciences, 46: 1478-1483.

Love, M. S., J. E. Caselle \& L. Snook. 2000. Fish assemblages around seven oil platforms in the Santa Barbara Channel area. Fishery Bulletin, 98: 96-117.

Mallet, D. \& D. Pelletier. 2014. Underwater video techniques for observing coastal marine biodiversity: a review of sixty years of publications (1952 - 2012). Fisheries Research, 154: 44-62.

Morrison, A. E. \& K. E. Gregor. 2012. Snapper (Pagrus auratus) Abundance and Size at Tūhua Marine Reserve as Determined by Baited Underwater Video (BUV) Survey. Rotorua, East Coast Bay of Plenty Conservancy, Department of Conservation. Technical Report, Series 6.

Pfister, R. P. \& D. Goulet. 1999. Nonintrusive video technique for in situ sizing of coral reef fishes. Copeia, 1999: 789-793.

Priede, I. G., P. M. Bagley, A. Smith, S. Creasey \& N. R. Merrett. 1994. Scavenging deep demersal fishes of the Porcupine Seabight, north-east Atlantic: observations by baited camera, trap and trawls. Journal of the Marine Biological Association of the United Kingdom, 74: 481-498.

Priede, I. G., K. L. Smith \& J. D. Armstrong. 1990. Foraging behavior of abyssal grenadier fish: inferences from acoustic tagging and tracking in the North Pacific Ocean. Deep Sea Research, 37: 81-101.

R Development Core Team. 2012. R: A language and environment for statistical computing. Vienna: R Foundation for Statistical Computing. Available from: http://www.R-project.org/ (July 2013).

Rochet, M. J., J. F. Cadiou \& V. M. Trenkel. 2006. Precision and accuracy of fish length measurements obtained with two visual underwater methods. Fishery Bulletin, 104: 1-9.

Roux de Buisson, P. E. 2010. Poor Knights Islands Marine Reserve and Mimiwhangata Marine Park fish monitoring 2009. Unpublished report prepared for the Department of Conservation Northland Conservancy. Available from: http://www.marinenz.org.nz/documents/poor-knights-fishmonitoring-2009.pdf, (February 2014).
Schobernd, Z. H., N. M. Bacheler \& P. B. Conn. 2014. Examining the utility of alternative video monitoring metrics for indexing reef fish abundance. Canadian Journal of Fisheries and Aquatic Sciences, 71: 464-471.

Shortis, M. R., E. S. Harvey \& D. Abdo. 2009a. A review of underwater stereo-image measurement for marine biology and ecology applications. Oceanography and Marine Biology: an Annual Review, 47: 257-292.

Shortis, M. R., J. W. Seager, A. Williams, B. A. Barrer \& M. Sherlock. 2009b. Using stereo video for deep water benthic habitat surveys. Marine Technology Society Journal, 42: 28-37.

Stobart, B., J. A. García-Charton, C. Espejo, E. Rochel, R. Goñi, O. Reñones, A. Herrero, C. Romain Crec'hriou, P. Sandrine, M. Concepción, P. Serge \& A. Pérez-Ruzafa. 2007. A baited underwater video technique to assess shallow-water Mediterranean fish assemblages: methodological evaluation. Journal of Experimental Marine Biology and Ecology, 345: 158-174.

Stokesbury, K. D. E., B. P. Harris, M. C. Marino II \& J. I. Nogueira. 2004. Estimation of sea scallop abundance using a video survey in off-shore US waters. Journal of Shellfish Research, 23: 33-40.

Stoner, A. W. 2004. Effects of environmental variables on fish feeding ecology: implications for the performance of baited fishing gear and stock assessment. Journal of Fish Biology, 65: 1445-1471.

Thompson, A. A. \& B. D. Mapstone. 2002. Intra- versus interannual variations in counts of reef fishes and interpretations of long-term monitoring studies. Marine Ecology Progress Series, 232: 247-257.

Thresher, R. E. \& J. S. Gunn. 1986. Comparative analysis of visual census techniques for highly mobile, reef-associated piscivores (Carangidae). Environmental Biology of Fishes, 17: 93-116.

Watson, D. L., E. S. Harvey, M. J. Anderson \& G. A. Kendrick. 2005. A comparison of temperate reef fish assemblages recorded by three underwater stereo-video techniques. Marine Biology, 148: 415-425.

Willis, T. J. \& R. C. Babcock. 2000. A baited underwater video system for the determination of relative density of carnivorous reef fish. Marine and Freshwater Research, 51: 755-763.

Willis T. J., R. B. Millar \& R. C. Babcock. 2000. Detection of spatial variability in relative density of fishes: comparison of visual census, angling, and baited underwater video. Marine Ecology Progress Series, 198: 249-260.

Wraith, J. A. 2007. Assessing reef fish assemblages in a temperate marine park using baited remote underwater video. Unpublished Ph.D. Dissertation, University of Wollongong, Wollongong, Australia, 88p.

Yoccoz, N. G., J. D. Nichols \& T. Boulinier. 2001. Monitoring of biological diversity in space and time. Trends in Ecology and Evolution, 16: 446-453.

Submitted July 15, 2014 Accepted October 5, 2014 by Francisco Gerson Araújo Published March 31, 2015 